www.jmscr.igmpublication.org

Impact Factor 5.84

Index Copernicus Value: 71.58

ISSN (e)-2347-176x ISSN (p) 2455-0450

crossref DOI: _https://dx.doi.org/10.18535/jmscr/v5i10.74

Journal Of Medical Science And Clinical Research

\title{
Study of effect of testicular perfusion and fertility in patient operated for inguinal hernia with mesh
}

\author{
Authors \\ Dr Iswara Chandra Mudulli, Dr Vikram Kumar Behera , Dr Sworupa Nanda Mallick, \\ Dr V. Rajesh, Dr Subhasis Patra , Dr Pradipta Kumar Sahoo, Dr Dushmanta Sethi
}

\begin{abstract}
Background: Inguinal hernia repair with synthetic mesh is the most common surgical procedure in India as during this procedure synthetic mesh is placed closed contact with spermatic cord. Resulting fibrosis may influence testicular perfusion this change is studied colour doppler study.

Method: prospective randomised study testicular perfusion was investigated before repair and after half yearly thereafter by dolour Doppler ultrasonography. Fourty two patients who underwent elective mesh hernia repair and also underwent preoperative and post-operative colour Doppler ultra-sonography were included in this study.

Results there was no significant difference in testicular blood flow or testicular blood volume were found.

Conclusion this study suggested that inguinal hernia repair with mesh has no significant effect over the testicular blood flow testicular volume or semen quality.

Keyword inguinal hernia testicular perfusion.
\end{abstract}

\section{Introduction}

Inguinal hernia repair is the most common surgical procedure performed worldwide. In this procedure as mesh is placed in close approximation to the spermatic cord and mesh-induced fibrosis or direct iatrogenic damage may affect the structures of the spermatic cord and impair testicular function and fertility. Potentially harmful complications of this procedure include obstructive azoospermia, ischemic orchitis, or testicular atrophy which has been experimentally proved. A systematic review on male infertility following inguinal hernia repair was recently conducted; however, the majority of procedures were open $(99.5 \%)$ and unilateral $(>80 \%)$. Men undergoing bilateral mesh hernia repair or unilateral hernia repair with pre-existing impairment of the contra lateral testis are considered to beat greatest risk of fertility impairment, but relevant large and prospective clinical trials on endoscopic bilateral hernia repair are lacking. The objective of this study was to evaluate the effect of inguinal hernia repairon male fertility by analysing testicular perfusion and volume, semen analysis.

Colour Doppler ultrasound (CDUS) is extremely helpful in demonstrating testicular blood flow in selected patients. The postoperative use of testicular CDUS to evaluate the preservation of testicular circulation has been reported after orchidopexy, excision of haematocele, and hernia repair. We discuss the previously unreported use 
of testicular CDUS in patients who underwent mesh hernia repair.

\section{Materials and Methods}

This was a prospective observation study done. From 1 January 2016 to 30 February 2017, a total number of 182 men were operated on for primary inguinal hernia at General Surgery Department M.K.C.G Medical college Berhampur, Odisha, India. From 182 patients only 42 patients were able to complete follow-up period for 6 months. Testicular perfusion and volume were determined by measuring the blood flow velocity $(\mathrm{cm} / \mathrm{s})$ by colour Doppler ultrasonography (CDUS) and grey-scale while fertility is assessed by semen volume, concentration, motility, or $\mathrm{pH}$.

Table 1 testicular perfusion and other related parameter

\begin{tabular}{|l|c|c|c|}
\hline Preoperative Postoperative & P value \\
\hline Testicular volume $(\mathrm{cm} 3)$ & $10.6 \pm 4.2$ & $10.9 \pm 3.8$ & $\mathrm{NS}$ \\
\hline Testicular perfusion $(\mathrm{cm} / \mathrm{sec})$ & $0.030 \pm 0.18$ & $0.032 \pm 0.08$ & $\mathrm{NS}$ \\
\hline Peak systolic velocity & $11.4 \pm 1.4$ & $10.8 \pm 1.2$ & $\mathrm{NS}$ \\
\hline End diastolic velocity & $2.6 \pm 03$ & $2.4 \pm 0.4$ & $\mathrm{NS}$ \\
\hline Acceleration time & $78.4 \pm 12.2$ & $74.4 \pm 14.2$ & $\mathrm{~S}$ \\
\hline
\end{tabular}

Table 2 fertility parameter (semen analysis)

\begin{tabular}{|l|c|c|c|}
\hline \multicolumn{4}{|l|}{ Preoperative Post operative P value } \\
\hline Volume (mL) & $3.4 \pm 0.4$ & $3.2 \pm 0.4$ & NS \\
\hline Motility (\% progression) & $44 \pm 8$ & $38 \pm 6$ & $\mathrm{~S}$ \\
\hline Concentration(106 cells/mL) & $46 \pm 6$ & $40 \pm 4$ & $\mathrm{NS}$ \\
\hline $\mathrm{pH}(\mathrm{mol} / \mathrm{L})$ & $7.7 \pm 0.4$ & $7.7 \pm 0.6$ & $\mathrm{NS}$ \\
\hline
\end{tabular}

\section{Results}

As per the above study there was no significant changes in blood flow and fertility parameters when comparing both pre- and postoperatively.

\section{Discussion}

The aim of my study was to see the effect of hernia repair on testicular circulation and fertility. And in our study we found there was no significant changes in blood circulation or fertility before and after operation.

In testis artery and veins are richly anastomosed thus protecting it from ischemia. Still in hernioplasty have some rare complication like testicular atrophy due to overzealous ligation or use of diathermy or iatrogenic dissection of cord.
Uzzo et al, who first investigated the influence of the Lichtenstein and Should ice operation on the cord structures in a canine model. They observed no significant differences regarding testicular volume, temperature, blood flow, and vasograms between the operation groups and preoperative and postoperative results, respectively. Fitzgibbons et al observed mesh adheres to the cord structures without erosion. Experimental histological study has shown normal spermatogenesis postoperatively. Fertility parameter like semen analysis has also show insignificant changes after operation.

Our study was limited due to small sample size addition to that decrease of sample in follow up also. And as mesh related inflammatory reaction subsides within 6 months so our study was limited with 6 month follow up. As after this time period there will be hardly any change in perfusion or fertility due to surgery.

In conclusion from the study suggest that there no relevant long term effect of hernia repair on testicular perfusion and fertility.

\section{References}

1. Simons MP, Aufenacker T, Bay-Nielsen M et al (2009) European Hernia Society guidelines on the treatment of inguinal hernia in adult patients. Hernia 13(4):343403

2. Bay-Nielsen M, Kehlet H, Strand L et al (2001) Quality assessment of 26304 herniorrhaphies in Denmark: a prospective nationwide study. Lancet 358(9288):11241128

3. Osman Nuri Dilek et al. Are There Adverse Effects of Herniorrhaphy Techniques on Testicular Perfusion? Evaluation by Color Doppler Ultrasonography UrolInt 2005;75:167-169

4. Jurgen Zieren, M.D. et al. Sexual function and testicular perfusion after inguinal hernia repairwith mesh The American Journal of Surgery 181 (2001) 204-206 
5. Amid PK, Shulman AG, Lichtenstein IL. Selecting synthetic mesh forthe repair of groin hernia. Postgrad Gen Surg1992; 4:150-5.

6. Uzzo RG, Lemack GE, Morissey KP, Goldstein M. The effects of mesh bioprothesis on the spermatic cord structures: a preliminary report in a canine model. J Urol1999;161:1344-9.

7. Fitzgibbons RJ, Salerno GM, Filipi CJ, et al. A laparoscopic intraperitoneal onlay mesh technique for the repair of an indirect inguinalhernia. Ann Surg1994;219:14456.

8. Klinge U, Klosterhalfen $\mathrm{B}, \mathrm{Mu}$ "ller $\mathrm{M}$, et al. Shrinking of polypropylene mesh in vivo: an experimental study in dogs. Eur J Surg1998;164:965-9. 